\title{
The measurement of revenue inefficiency over time: An additive perspective
}

\author{
Samah Jradi ${ }^{a}$, Tatiana Bouzdine Chameeva ${ }^{a}$, Juan Aparicio ${ }^{\mathrm{b}, *}$ \\ a Kedge Business School, Talence, 680 Cours Libération 33405, France \\ ${ }^{\mathrm{b}}$ Center of Operations Research (CIO), University Miguel Hernandez of Elche (UMH), Elche, Alicante 03202, Spain
}

\section{A R T I C L E I N F O}

\section{Article history:}

Received 29 January 2017

Accepted 19 February 2018

Available online xxx

\section{Keywords:}

Data envelopment analysis

Revenue Luenberger-type indicator

Weighted additive distance function

French wine regions

Common market organization

\begin{abstract}
A B S T R A C T
In this paper, we measure and decompose revenue inefficiency over time while accounting for all sources of technical inefficiencies. Our proposed decomposition exploits the dual relationship between the weighted additive distance function and revenue inefficiency in Aparicio et al. [1]. With the aid of the Luenberger indicator, we decompose this indicator into productivity change, and overall allocative change components. The importance of such decomposition is that it provides a complete picture of the sources of productivity change, thus obtaining a slack free allocative component. Finally, the model is applied to the French wine sector to illustrate its practicality: we track how revenue inefficiency evolves in French wine regions over the 2004-2013 period, before and after the implementation of Common Market Organization policies in Europe in 2008.
\end{abstract}

(c) 2018 Elsevier Ltd. All rights reserved.

\section{Introduction}

Economic (overall) efficiency measurement based on the approach initiated by Farrell [2] has received a lot of attention from academics and practitioners. Economic efficiency originates from two different sources, technical efficiency and allocative efficiency. In the spirit of Farrell's renowned decomposition, technical efficiency is estimated in the first place, for the evaluated firm, as some measure of the gains obtained from moving to the frontier of the production possibility set. Allocative efficiency is then estimated as a residual. The main argument behind this approach is that the measurement of allocative efficiency presumes technical efficiency. This is due to the fact that, only on the production isoquant, the rate of substitution between production inputs is welldefined and comparable with the ratio of input market prices in an output-oriented setting. Therefore, under the Farrell approach, the analysis focuses on the corresponding isoquant before estimating allocative efficiency. Specifically, Farrell [2] resorted to radial (equiproportional) movements in order to measure technical effi-

\footnotetext{
This manuscript was processed by Associate Editor C-M Chen.

* Corresponding author.

E-mail addresses: samah.jradi@kedgebs.com (S. Jradi), tatiana.chameeva@ kedgebs.com (T. Bouzdine Chameeva), j.aparicio@umh.es (J. Aparicio).
}

ciency, relating this particular component to both the coefficient of resource utilization ${ }^{1}$ of Debreu [3] and the inverse of the Shephard distance function [4]. In this way, cost efficiency can be decomposed into technical efficiency and allocative efficiency.

By analogy, a firm's revenue efficiency can be decomposed into technical and allocative efficiency. Technical efficiency measures how close the firm is to the corresponding isoquant, whereas allocative efficiency for technically efficient units, measures the loss due to being sub-optimal under given market prices.

Although revenue and cost efficiency have been traditionally defined and studied with cross-sectional data in the literature, it is also of interest to determine how these inefficiencies change over time when panel data are available. Moreover, identifying the drivers of the inefficiency change is also relevant from a managerial point of view. So, if information on market prices is known, it seems necessary to define Malmquist-type indexes or/and Luenberger-type indicators when decision-makers are assumed to be revenue maximizers or cost minimizers. In this respect, Maniadakis and Thanassoulis [5], Zhu et al. [6] have defined and decomposed a cost Malmquist index, and Juo et al. [7] have

\footnotetext{
1 The coefficient of resource utilization is the name that [3], working in the commodity space, used for referring to a 'radial' measure of the efficiency of an economic system.
} 
introduced a Luenberger indicator than can be applied in these situations.

In this paper, we measure and decompose revenue inefficiency over time, while accounting for all sources of technical inefficiencies (slacks) using the Luenberger indicator. Obviously, radial measures of efficiency in the presence of non-zero slacks lead to an overestimation in the technical efficiency of the decision making units (DMUs) being assessed. To overcome such biased estimation, we account for the weighted additive distance function (WADF) that fully incorporates all sources of technical inefficiency. Our proposed decomposition exploits the dual relationship between the weighted additive (WA) model and revenue inefficiency to consider technical and allocative components. The importance of such decomposition is that a DMU gains a better knowledge about its revenue efficiency, resulting from the productivity change and allocative (slack free) components. Within this context, the assessed DMU will be able to identify its inefficiencies arising from technical sources as well as recognizing the importance of the best combination of input-output mixes to improve its revenue efficiency over time. Also, this decomposition overcomes the problem of homogeneity of degree one for prices of the index, hence it provides an independent unit measure of currencies.

Apart from accounting for slacks, the WADF function is always feasible, so it allows the determination of values related to the performance of points located in both the interior and exterior of the reference production possibility set. In this way, it is possible to determine improvements and regresses over time for consecutiveperiods while accounting for slacks. Moreover, the decomposition of profit inefficiency could be implemented in a similar way to account for both input reduction and output expansion at the same time. The latter characteristic excels the Malmquist index which is defined only from an output-oriented or an input-oriented perspective.

In the literature, several studies have incorporated slacks to measure economic or productivity change over time. Grifell-Tatjé et al. [8] proposed a quasi-Malmquist index based on the WA model introduced by Lovell et al. [9] to measure productivity change over time. However, the authors did not show how this index could be decomposed into different sources of inefficiency (technical and efficiency change). Tone [10] developed a slack based measure to assess productivity change over time. However, the model suffered from infeasibility problems while assessing consecutive periods. To overcome this problem, Tone [11] introduced a new Data Envelopment Analysis (DEA) model that always leads to feasibility, based on a Malmquist index. Again, the decomposition of productivity change was not introduced. On the other hand, Grifell-Tatjé and Lovell [12], Asaftei [13], and Juo et al. [14] used different DEA measures to analyze the profit change over time. However, all the measures in the paper are unit price dependent i.e. affected by price currencies. Recently, Juo et al. [7] decomposed profit inefficiency based on the dual relationship between the profit inefficiency and the directional distance function using a Luenberger-type indicator. This decomposition overcomes the unit dependence issue; nevertheless it does not account for slacks.

As an application for the new methodology, we consider the French wine sector to measure the revenue inefficiency of the nine major French wine regions for the 2004-2013 period, before and after the implementation of Common Market Organization (CMO) policies.

Over the past decades, wine production has been France's second largest export sector, and the economic performance of the French wine industry is of paramount importance for the country's economic health. The CMO establishes measures that enable the European Union to monitor and manage the markets of agricultural products. The purpose of the $\mathrm{CMO}$, specifically in the wine sector, is to reduce production surplus, strengthen the EU reputation of quality wine and increase the competitiveness of EU wine producers in the world market. In April 2008, the CMO set multiple measures such as grubbing-up, planting rights, national envelopes, promotion in third-country markets, crisis distillation scheme, and rural development funding to help in accomplish those aims. Moreover, this policy distinguished between the Protected Designation of Origin (PDO) and the Protected Geographical Indication (PGI) where detailed rules are found in EU Regulation N 479. These measures have had a serious impact on the French wine economy (see for example [15]). This phenomenon aroused our curiosity to explore the efficiency of French wine regions before and after implementation of CMO policy.

The paper proceeds as follows. In Section 2, we present the existing approaches for measuring and decomposing overall inefficiency. In Section 3, we show how to measure and decompose the new revenue Luenberger-type indicator based on the WADF. In Section 4, we describe and analyze the data used for the French wine sector application. Finally, in Section 5, we present our conclusions.

\section{Preliminaries}

Data envelopment analysis (DEA) is a well-established nonparametric methodology used for the assessment of technical efficiency of a set of decision making units (DMUs) that utilize several inputs to produce several outputs. DEA offers a range of different models (oriented and non-oriented models, radial, additive, directional-based measures, etc.) to assess the technical efficiency of the given DMUs. Choosing the appropriate model is accompanied by a fundamental assumption concerning the return to scale of the production technology. The constant returns to scale (CRS) model introduced by Charnes et al. [16], also known as the CCR model, assumes that output increases by the same proportional change of all inputs. On the other hand, the variable return to scale model (VRS) introduced by Banker et al. [17], also known as the BCC model, assumes that output does not necessarily increase by the same proportional change of all inputs.

The literature on DEA has reported its applications to various industries including the wine sector. However, the literature on the wine DEA application is quite poor. One of the first publications was the work of Townsend et al. [18] who provided data from the wine producing areas in Western Cape of South Africa to disclaim the inverse relationship between farm size and productivity measures. The variations in wine prices in Bordeaux by taking into account weather data has been the focus of Lecocq and Visser [19] work. Later on, Barros et al. [20] used an output oriented technical efficiency index to compare the efficiency of cooperative and private wine enterprises in Portugal, while Arandia Miura and Aldanondo Ochoa [21] compared the technical and environmental efficiencies of organic and conventional wine farms. Henriques et al. [22] used panel data for the period (2000-2005) to analyze the technical efficiency of wine producing farms in Portugal, and Fuller et al. [23] investigated the cost savings than can be attained from developing powdery mildew resistant grape varieties. Vidal et al. [24] studied the performance efficiency of Spanish PDO wine, using a Bounded Adjusted DEA Measure [25]. Pastor et al. [26] used a constant return to scale and variable return to scale Bounded Adjusted DEA Measure to analyze the productivity of the Spanish wine sector. Aparicio et al. [27] used an output oriented WA model to decompose revenue inefficiency. This decomposition was based on adopting technical efficiency measures that account for slacks, thus providing more realistic values. 


\subsection{Description of the DEA models}

Working in the usual DEA framework, let us consider $\mathrm{n}$ decision making units (DMUs) to be evaluated. $D M U_{j}$ consumes $X_{j}=$ $\left(x_{1 j}, x_{2 j}, \ldots, x_{m j}\right) \in R_{+}^{m}$ amounts of input for the production of $Y_{j}=$ $\left(y_{1 j}, y_{2 j}, \ldots, y_{s j}\right) \in R_{+}^{s}$ amounts of output. The relative efficiency of each DMU in the sample is assessed with reference to the so-called production possibility set, which can be empirically constructed in DEA from the observations by assuming several postulates (see, [17]). The production possibility set in DEA can then be characterized using VRS as follows:

$$
\begin{gathered}
T_{V R S}=\left\{(X, Y) \in R_{+}^{m} \times R_{+}^{S}: X \geq \sum_{j=1}^{n} \lambda_{j} x_{j}, Y \leq \sum_{j=1}^{n} \lambda_{j} y_{j},\right. \\
\left.\sum_{j=1}^{n} \lambda_{j}=1, \lambda_{j} \geq 0, j=1, \ldots, n\right\}
\end{gathered}
$$

In standard microeconomics theory, the economic behavior of the firm is usually characterized by cost minimization, revenue maximization or profit maximization. Obviously, the choice of an economic approach of the firm depends, in part, on what assumptions one is willing to make. If we assume that firms face exogenously determined output and input prices, then the objective of these firms is to choose the input and output combinations that result in maximum profit at applicable market prices. Let us denote maximum profit as $\Pi(Q P)$, given input and output price vectors $Q=\left(q_{1}, q_{2}, \ldots, q_{m}\right) \in R_{++}^{m}$ and $P=\left(p_{1}, p_{2}, \ldots, p_{s}\right) \in$ $R_{++}^{s}$, respectively. The traditional profit inefficiency measure that can be found in the literature compares the observed profit for firm $0, \Pi_{0}=$ Revenue - cost $=\sum_{r=1}^{s} p_{r} y_{r 0}-\sum_{i=1}^{m} q_{i} x_{i 0}$, with the optimal level of profit. There exists two different ways to assess the profit inefficiency. On the one hand, we could use a ratio-form measure as $\frac{\Pi_{0}}{\Pi(Q, P)}$. Unfortunately, if the optimal profit, $\Pi(Q P)$, is zero then this ratio is not well defined. A second alternative to evaluate profit inefficiency involves the use of a difference-form measure as $\Pi(Q, P)-\Pi_{0}$. This measure takes only non-negative values since, by definition, $\Pi(Q, P) \geq \Pi_{0}$. Also, a value of zero is related to nil inefficiency for the rated firm.

As for this second alternative, it is worth mentioning that Nerlove [28] was the first to suggest the difference between optimal and actual profit as a measure of inefficiency. This measure has one serious limitation. Specifically, it is homogeneous of degree one in prices. A solution to this problem was proposed by Chambers et al. [29] using a price normalization obtained from the existing duality between the directional technology distance function and the profit function. Vector $g=\left(g_{x}, g_{y}\right)$ is the predefined vector that directs the projection of the assessed point to reach the frontier of the technology (see Section 3.2).

$$
\frac{\Pi(Q, P)-\Pi_{0}}{\sum_{r=1}^{S} p_{r} g_{y r}+\sum_{i=1}^{m} q_{i} g_{x i}}
$$

The last expression may be decomposed into technical efficiency and allocative efficiency by resorting to the Directional Distance Function (DDF). However, in this decomposition, technical efficiency is determined through the DDF, which neglects slacks (see, [30]), and consequently does not take into account all sources of technical inefficiency. This feature implies that technical inefficiency is underestimated by the DDF approach, thus overestimating the allocative term. Therefore, Cooper et al. [31] aimed to decompose profit inefficiency through accounting for slacks in the technical inefficiency measure component, i.e. having an allocative component free of slacks. Cooper et al. [31] proposed a new normalized measure for the decomposition of profit inefficiency by means of a WA DEA model, which is given by (3) under VRS:

$$
\begin{aligned}
W A\left(X_{0}, Y_{0} ; W^{-}, W^{+}\right):= & \max \sum_{i=1}^{m} w_{i}^{-} s_{i 0}^{-}+\sum_{r=1}^{s} w_{r}^{+} s_{r 0}^{+}, \\
& s . t \\
& \sum_{j=1}^{n} \lambda_{j 0} x_{i j}+s_{i 0}^{-} \leq x_{i 0}, \quad i=1, \ldots, m \\
& \sum_{j=1}^{n} \lambda_{j 0} y_{r j}-s_{r 0}^{+} \geq y_{r 0}, \quad r=1, \ldots, s \\
& \sum_{j=1}^{n} \lambda_{j 0}=1, \\
& s_{i 0}^{-} \geq 0, \quad i=1, \ldots, m \\
& s_{r 0}^{+} \geq 0, \quad r=1, \ldots, s \\
& \lambda_{j 0} \geq 0, \quad j=1, \ldots, n .
\end{aligned}
$$

$D M U_{0}$ is said to be Pareto-Koopman efficient if and only if $W A\left(X_{0}, Y_{0}, W^{-}, W^{+}\right)=0$. Using duality theory, Cooper et al. [31] proved the following inequality:

$\frac{\Pi(Q, P)-\Pi_{0}}{\min \left[\frac{q_{1}}{w_{1}^{-}}, \ldots, \frac{q_{m}}{w_{m}^{-}}, \frac{p_{1}}{w_{1}^{+}}, \ldots, \frac{p_{s}}{w_{s}^{+}}\right]} \geq W A\left(X_{0}, Y_{0} ; W^{-}, W^{+}\right)$.

where $\quad W^{-}=\left(w_{1}^{-}, w_{2}^{-}, \ldots, w_{m}^{-}\right) \in R_{++}^{m} \quad$ and $\quad W^{+}=$ $\left(w_{1}^{+}, w_{2}^{-}, \ldots, w_{s}^{+}\right) \in R_{++}^{s}$ are predefined input and output weights respectively that represent the relative importance of unit inputs and unit outputs. In our study, we have chosen the output weights to be $\frac{1}{s y_{s t}}$. Nevertheless, from the existing literature, there are several possibilities to select the input and output weights: the Measure of Inefficiency Proportions (MIP) [32], the Range Adjusted Measure of Inefficiency (RAM)[32], the Bounded Adjusted Measure of Inefficiency (BAM) [25], and the normalized WA model [33].

The profit inefficiency (PI), i.e the left hand side of expression (4), measures the profit loss of the assessed DMU. Dividing by $\min \left[\frac{q_{1}}{w_{1}^{-}}, \ldots, \frac{q_{m}}{w_{m}^{-}}, \frac{p_{1}}{w_{1}^{+}}, \ldots, \frac{p_{s}}{w_{s}^{+}}\right]$makes PI homogenous of degree zero, i.e. the measure becomes unit invariant for the input and output prices. The WA model in (3) accounts for slacks, in which it seeks the possible input reduction and the possible output augmentation at the same time.

We note that input and output oriented WA models exist, and they are found in some literature such as Grifell-Tatjé et al. [8], Lovell and Pastor [33], Cooper and Pastor [34], Prieto and Zofio [35], and Cook and Hababou [36]. In particular, in this paper we will resort to the output-oriented WA model in DEA.

As we have mentioned before, Farrell specified two sources of overall inefficiency, which are the technical and allocative inefficiency. Returning to inequality (4), this inequality can be rendered by adding the allocative inefficiency residual component to the right hand side to obtain:

$\frac{\Pi(Q, P)-\Pi_{0}}{\min \left[\frac{q_{1}}{w_{1}^{-}}, \ldots, \frac{q_{m}}{w_{m}^{-}}, \frac{p_{1}}{w_{1}^{+}}, \ldots, \frac{p_{s}}{w_{s}^{+}}\right]}=W A\left(X_{0}, Y_{0} ; W^{-}, W^{+}\right)+A I$.

\section{Methodology}

\subsection{Revenue inefficiency decomposition}

In our research, we adopt the methodology presented in the [27] work to decompose revenue inefficiency. The idea of this decomposition is based on Cooper et al. [31] that dealt with the decomposition of profit inefficiency.

Following the same steps as Aparicio et al. [27], Cooper et al. [31] derived a new inequality similar to (4), by taking into consideration the output oriented version of the WA model. This type 
of models is interested in maximizing outputs while keeping the same amount of inputs unchanged, as illustrated by the following linear programming program:

$$
\begin{aligned}
W A_{0}\left(X_{0}, Y_{0}\right):= & \max \sum_{r=1}^{s} \frac{s_{r 0}^{+}}{s y_{r 0}} \\
& s . t \\
& \sum_{j=1}^{n} \lambda_{j 0} x_{i j} \leq x_{i 0}, \quad i=1, \ldots, m \\
& \sum_{j=1}^{n} \lambda_{j 0} y_{r j}=y_{r 0}+s_{r 0}^{+}, \quad r=1, \ldots, s \\
& \sum_{j=1}^{n} \lambda_{j 0}=1, \\
& s_{r 0}^{+} \geq 0, \quad r=1, \ldots, s \\
& \lambda_{j 0} \geq 0, \quad j=1, \ldots, n .
\end{aligned}
$$

As we can see, to obtain this output-oriented version of the general WA model, $W A\left(X_{0}, Y_{0} ; W^{-}, W^{+}\right)$, we choose $W^{-}=(0,0, \ldots, 0)=$ $0_{m}$ and $W^{+}=\left(\frac{1}{s y_{10}}, \frac{1}{s y_{20}}, \ldots, \frac{1}{s y_{s 0}}\right)$. The main property of this model is that obtaining an optimal value of zero means that the assessed $D M U_{0}$ is Pareto-Koopman efficient in $P\left(X_{0}\right)=\left\{Y \in R_{+}^{s}:\left(X_{0}, Y\right) \in\right.$ $\left.T_{V R S}\right\}$, otherwise it is technically inefficient. After introducing the output-oriented WA model, Aparicio et al. [27] derived a similar inequality to that of Cooper et al. [31] as shown below:

$$
\frac{R\left(P, X_{0}\right)-R_{0}}{\min \left[p_{1} s y_{10}, \ldots, p_{s} s y_{s 0}\right]} \geq W A\left(X_{0}, Y_{0}\right)
$$

where $R\left(P, X_{0}\right)$ is the maximum feasible revenue given the output price vector $P=\left(p_{1}, p_{2}, \ldots, p_{s}\right) \in R_{++}^{s}$, and $R_{0}$ is the actual revenue of $D M U_{0}$ given by $R_{0}=\sum_{r=1}^{S} p_{r} y_{r 0}$. Again, this inequality is rendered by adding the allocative inefficiency component to obtain the following equation similar to (5)

$\frac{R\left(P, X_{0}\right)-R_{0}}{\min \left[p_{1} s y_{10}, \ldots, p_{s} s y_{s 0}\right]}=W A\left(X_{0}, Y_{0}\right)+A I\left(P_{0}, X_{0}, Y_{0}\right)$

It is worth noting that the revenue inefficiency, the left hand side of (8), is always greater or equal to zero. Obtaining a zero value means that the assessed DMU has achieved the maximum feasible revenue i.e. $R_{0}=R\left(P, X_{0}\right)$.

The approach by Aparicio et al. [27] established a dual correspondence between the revenue function and the output-oriented WA model. Hence, the revenue inefficiency decomposition overcame the decomposition gap between the optimal and actual revenue by adopting technical efficiency measures that account for all sources of inefficiencies in the output space.

\subsection{Revenue Luenberger indicator}

The paper of Aparicio et al. [27] worked on a single period of time. In contrast, in this paper, we will deal with panel data. Accordingly, we will introduce a new measure of revenue inefficiency change over time. In this way, we extend the [27] approach to the panel data context. A revenue Luenberger-type indicator is characterized by its additive structure unlike the Malmquist index, which is multiplicative in nature. Therefore, it is the suitable indicator to use with the WA model.

The Luenberger productivity indicator, initially proposed in Chambers et al. [37], Chambers and Pope [38] and Chambers [39], between $t$ and $t+1$ for unit 0 is given by: $\frac{1}{2}\left[\left(D_{t}\left(X_{0 t}, Y_{0 t}, g_{X}, g_{Y}\right)-D_{t}\left(X_{0 t+1}, Y_{0 t+1}, g_{X}, g_{Y}\right)\right)+\left(D_{t+1}\left(X_{0 t}, Y_{0 t}, g_{X}\right.\right.\right.$, $\left.\left.\left.g_{Y}\right)-D_{t+1}\left(X_{0 t+1}, Y_{0 t+1}, g_{X}, g_{Y}\right)\right)\right]$ where $D_{t}\left(X_{0 t}, Y_{0 t}, g_{X}, g_{Y}\right)$ is the directional distance function that provides a direct measure of how far the assessed point $\left(X_{0 t}, Y_{0 t}\right)$ must be projected along a predefined vector $\left(g_{X}, g_{Y}\right)$ to reach the frontier of the technology at time $\mathrm{t}\left(T_{t}\right)$, defined as:

$$
\begin{aligned}
& D_{t}\left(X_{0 t}, Y_{0 t}, g_{X}, g_{Y}\right)= \\
& \left\{\begin{array}{l}
\max \left\{\beta \in R,\left(X_{0 t}-\beta g_{X}, Y_{0 t}+\beta g_{Y}\right) \in T\right\}, g_{X_{0 t}} \in R_{+}^{m}, \quad g_{Y_{0 t}} \in R_{+}^{s}, \\
-\infty \text { otherwise. }
\end{array}\right.
\end{aligned}
$$

Briec and Kerstens [40] showed that the directional distance functions underlying this productivity indicator maybe ill-defined while assessing consecutive periods, since it can lead to infeasibilities if the dimension of the output space is greater or equal to two. However, the authors have proved that the use of any direction vector $\mathrm{g}$ of the form $g=\left(h\left(X_{0}\right), c Y_{0}\right) \in R_{+}^{m} \times R_{++}^{s}$ guarantees feasibility for all points $\left(X_{0}, Y_{0}\right) \in R_{+}^{m} \times R_{++}^{s}$ given that $\mathrm{c} \in R_{++}$and $h: R_{+}^{m} \rightarrow R_{+}^{m}$. This means that for all pairs of technologies $T_{t}$ and $T_{t+1}$ that satisfy certain axioms, which are verified by the DEA technologies under CRS, then the Luenberger productivity indicator (based on DDF measure) is well-defined. Moreover, it is obvious that the technical efficiency is highly subjective to the choice of the direction vector. To overcome this limitation, we adopt the WADF introduced by Aparicio et al. [41], instead of the DDF, to decompose our revenue Luenberger indicator, defined as:

$$
\begin{gathered}
\operatorname{DWA}\left(X_{0}, Y_{0} ; W^{-}, W^{+}\right)=\max \left\{W A^{+}\left(X_{0}, Y_{0} ; W^{-}, W^{+}\right),\right. \\
\left.W A^{-}\left(X_{0}, Y_{0} ; W^{-}, W^{+}\right)\right\}
\end{gathered}
$$

where

$$
\begin{aligned}
W A^{+}\left(X_{0}, Y_{0} ; W^{-}, W^{+}\right):= & \max \sum_{i=1}^{m} w_{i}^{-} s_{i 0}^{-}+\sum_{r=1}^{s} w_{r}^{+} s_{r 0}^{+}, \\
& s . t \\
& \sum_{j=1}^{n} \lambda_{j 0} x_{i j}+s_{i 0}^{-} \leq x_{i 0}, \quad i=1, \ldots, m \\
& \sum_{j=1}^{n} \lambda_{j 0} y_{r j}-s_{r 0}^{+} \geq y_{r 0}, \quad r=1, \ldots, s \\
& s_{i 0}^{-} \geq 0, \quad i=1, \ldots, m \\
& s_{r 0}^{+} \geq 0, \quad r=1, \ldots, s \\
& \lambda_{j 0} \geq 0, \quad j=1, \ldots, n .
\end{aligned}
$$

and

$$
\begin{aligned}
W A^{-}\left(X_{0}, Y_{0} ; W^{-}, W^{+}\right):= & \max \sum_{i=1}^{m} w_{i}^{-} s_{i 0}^{-}+\sum_{r=1}^{s} w_{r}^{+} s_{r 0}^{+}, \\
& s . t \\
& \sum_{j=1}^{n} \lambda_{j 0} x_{i j}+s_{i 0}^{-} \leq x_{i 0}, \quad i=1, \ldots, m \\
& \sum_{j=1}^{n} \lambda_{j 0} y_{r j}-s_{r 0}^{+} \geq y_{r 0}, \quad r=1, \ldots, s \\
& s_{i 0}^{-} \leq 0, \quad i=1, \ldots, m \\
& s_{r 0}^{+} \leq 0, \quad r=1, \ldots, s \\
& \lambda_{j 0} \geq 0, \quad j=1, \ldots, n .
\end{aligned}
$$

Models (9) and (10) are defined under CRS. Indeed, it is usual to assume constant returns to scale when the objective is measuring productivity change over time. This viewpoint has been followed since the papers by Grifell-Tatjé and Lovell [42], Ray and Desli [43], Balk [44] and Lovell [45] for the Malmquist productivity index and, likewise, for the Luenberger productivity indicator since its definition (see, for example, a recent application that follows this philosophy in Kapelko et al. [46]).

The $D W A\left(X_{0}, Y_{0} ; W^{-}, W^{+}\right)$model is always feasible and bounded, as we will go on to illustrate. If $\left(X_{0}, Y_{0}\right) \in T$, then program (9) is feasible and bounded with an optimal value greater 
or equal to zero, and program (10) is also feasible with an optimal value that equals zero. Thus, $D W A\left(X_{0}, Y_{0} ; W^{-}, W^{+}\right)$is equal to $W A^{+}\left(X_{0}, Y_{0} ; W^{-}, W^{+}\right)$, which coincides with the traditional WA model in DEA. However, if $\left(X_{0}, Y_{0}\right) \notin T$ then program (9) is infeasible with $W A^{+}\left(X_{0}, Y_{0}, W^{-}, W^{+}\right):=-\infty$, and program (10) is feasible and bounded with a value less than or equal to zero. Thus, $D W A\left(X_{0}, Y_{0} ; W^{-}, W^{+}\right)$coincides with $W A^{-}\left(X_{0}, Y_{0} ; W^{-}, W^{+}\right)$. Moreover, since both scenarios are excluding, the sign of the optimal value of program (9) or program (10) will determine whether $\left(X_{0}\right.$, $\left.Y_{0}\right)$ belongs to $\mathrm{T}$ or not, i.e. having $\mathrm{DWA}\left(\mathrm{X}_{0}, Y_{0} ; W^{-}, W^{+}\right) \geq 0$ if and only if $\left(X_{0}, Y_{0}\right) \in T$.

Additionally, the WADF can be output or input oriented simply by defining $W^{-}=0_{m}$ and $W^{+}=0_{s}$, respectively. As we have mentioned earlier, we aim to introduce and decompose a revenue Luenberger indicator (RLI) based on the WADF. So, by analogy with the cost Malmquist index in Zhu et al. [6] we define:

$$
\begin{aligned}
R L I= & \frac{1}{2}\left[\left(\frac{R_{t}\left(P_{t}, X_{t}\right)-P_{t} Y_{t}}{a}-\frac{R_{t}\left(P_{t}, X_{t+1}\right)-P_{t} Y_{t+1}}{b}\right)\right. \\
& \left.+\left(\frac{R_{t+1}\left(P_{t+1}, X_{t}\right)-P_{t+1} Y_{t}}{a^{\prime}}-\frac{R_{t+1}\left(P_{t+1}, X_{t+1}\right)-P_{t+1} Y_{t+1}}{b^{\prime}}\right)\right]
\end{aligned}
$$

where

$$
\begin{aligned}
a & =\min \left\{p_{1 t} s y_{1 t}, p_{2 t} s y_{2 t}, \ldots, p_{s t} s y_{s t}\right\} \\
b^{\prime} & =\min \left\{p_{1 t+1} s y_{1 t+1}, p_{2 t+1} s y_{2 t+1}, \ldots, p_{s t+1} s y_{s t+1}\right\}
\end{aligned}
$$

$a^{\prime}= \begin{cases}\min \left\{p_{1 t+1} s y_{1 t}, p_{2 t+1} s y_{2 t}, \ldots, p_{s t+1} s y_{s t}\right\} & \text { if }\left(X_{t}, Y_{t}\right) \in T_{t+1} \\ \max \left\{p_{1 t+1} s y_{1 t}, p_{2 t+1} s y_{2 t}, \ldots, p_{s t+1} s y_{s t}\right\} & \text { if }\left(X_{t}, Y_{t}\right) \notin T_{t+1}\end{cases}$ $b= \begin{cases}\min \left\{p_{1 t} s y_{1 t+1}, p_{2 t} s y_{2 t+1}, \ldots, p_{s t} s y_{s t+1}\right\} & \text { if }\left(X_{t+1}, Y_{t+1}\right) \in T_{t} \\ \max \left\{p_{1 t} s y_{1 t+1}, p_{2 t} s y_{2 t+1}, \ldots, p_{s t} s y_{s t+1}\right\} & \text { if }\left(X_{t+1}, Y_{t+1}\right) \notin T_{t}\end{cases}$

We note that a and b' are given from inequality (7). This proof was done based on the assumption that $Y \in P(X)$. However, in order to develop a revenue Luenberger indicator, in this paper we need to determine how revenue inefficiency is related to the WADF when $Y \notin P(X)$. The reason is the terms of the Luenberger indicator for consecutive periods: a unit of period $t$ is evaluated with respect to technology in $t+1$ and vice versa. To do that, we next present the proof of a' and b in Proposition 1.

Proposition 1. Given output market prices $P \in R_{++}^{s}, W^{+} \in R_{++}^{s}, X_{0}=$ $\left(x_{10}, \ldots, x_{m 0}\right) \in R_{+}^{m} \backslash\left\{0_{m}\right\}$ and $Y_{0} \notin P\left(X_{0}\right)$, then the following inequality holds:

$$
\begin{aligned}
& \frac{R\left(P, X_{0}\right)-\sum_{r=1}^{s} p_{r} y_{r 0}}{\max \left[\frac{p_{1}}{w_{1}^{+}}, \ldots, \frac{p_{s}}{w_{s}^{+}}\right]} \geq \operatorname{DWA}\left(X_{0}, Y_{0} ; 0_{m}, W^{+}\right) \\
& R L I=\underbrace{\left[\frac{R_{t}\left(P_{t}, X_{t}\right)-P_{t} Y_{t}}{a}-\frac{R_{t+1}\left(P_{t+1}, X_{t+1}\right)-P_{t+1} Y_{t+1}}{b^{\prime}}\right]}_{\text {OIEC }} \\
& +\underbrace{\frac{1}{2}\left[\frac{R_{t+1}\left(P_{t+1}, X_{t}\right)-P_{t+1} Y_{t}}{a^{\prime}}-\frac{R_{t}\left(P_{t}, X_{t}\right)-P_{t} Y_{t}}{a}+\frac{R_{t+1}\left(P_{t+1}, X_{t+1}\right)-P_{t+1} Y_{t+1}}{b^{\prime}}-\frac{R_{t}\left(P_{t}, X_{t+1}\right)-P_{t} Y_{t+1}}{b}\right]}_{\text {RLC }}
\end{aligned}
$$

Proof. Let us prove it for the profit function under VRS, since it can be translated to the output-oriented context. Following Aparicio et al. [1], if $\left(X_{0}, Y_{0}\right) \notin T$ then $D W A\left(X_{0}, Y_{0} ; W^{-}, W^{+}\right)=D W A^{-}$ where:

$$
\begin{aligned}
D W A^{-}\left(X_{0}, Y_{0} ; W^{-}, W^{+}\right) & =\min \sum_{r=1}^{s} v_{i 0} x_{i j}-\sum_{i=1}^{m} u_{r 0} y_{i j}+\delta_{0}, \\
& \text { s.t } \\
& \sum_{r=1}^{s} v_{i 0} x_{i j}-\sum_{i=1}^{m} u_{r 0} y_{i j}+\delta_{0} \geq 0, j=1, \ldots, n \\
& 0 \leq v_{i 0}^{-} \leq w_{i}^{-}, \quad i=1, \ldots, m \\
& 0 \leq u_{r 0}^{-} \leq w_{r}^{+}, \quad r=1, \ldots, s .
\end{aligned}
$$

Given market prices $(C, P) \in R_{++}^{m} \times R_{++}^{s}$, we have that $(\widehat{C}, \widehat{P})=$ $\frac{(C, P)}{\max \left[\frac{c_{1}}{w_{1}^{-}}, \ldots, \frac{c_{m}}{w_{m}^{-}}, \frac{p_{1}}{w_{1}^{+}}, \ldots, \frac{p_{s}}{w_{s}^{+}}\right]}$satisfies the last two constraint of (12). Regarding the first restriction, by the definition of the profit function, we have that $\Pi(\widehat{C}, \widehat{P}) \geq \sum_{r=1}^{S} \widehat{p_{r}} y_{r 0}-\sum_{i=1}^{m} \widehat{c}_{i} x_{i 0}$, for all $\mathrm{j}=1, \ldots, \mathrm{n}$. Consequently, $(\widehat{C}, \widehat{P}, \Pi(\widehat{C}, \widehat{P}))$ is a feasible solution of $(12)$. In this way, we have that

$$
\begin{aligned}
\operatorname{DWA}\left(X_{0}, Y_{0} ; W^{-}, W^{+}\right)= & D^{-}\left(X_{0}, Y_{0} ; W^{-}, W^{+}\right) \leq \Pi(\widehat{C}, \widehat{P}) \\
& -\left(\sum_{r=1}^{s} \widehat{p_{r}} y_{r 0}-\sum_{i=1}^{m} \widehat{c_{i}} x_{i 0}\right) \\
= & \frac{\Pi(C, P)-\left(\sum_{r=1}^{s} p_{r} y_{r 0}-\sum_{i=1}^{m} c_{i} x_{i 0}\right)}{\max \left[\frac{c_{1}}{w_{1}^{-}}, \ldots, \frac{c_{m}}{w_{m}^{-}}, \frac{p_{1}}{w_{1}^{+}}, \ldots, \frac{p_{s}}{w_{s}^{+}}\right]}
\end{aligned}
$$

which in the case of the output-oriented WADF can be translated into (14) if $Y_{0} \notin P\left(X_{0}\right)$.

$\frac{R\left(P, X_{0}\right)-\sum_{r=1}^{s} p_{r} y_{r 0}}{\max \left[\frac{p_{1}}{w_{1}^{+}}, \ldots, \frac{p_{s}}{w_{s}^{+}}\right]} \geq D W A\left(X_{0}, Y_{0} ; 0_{m}, W^{+}\right)$.

\subsection{Revenue Luenberger indicator decomposition}

In this section, we show how to decompose the revenue Luenberger-type indicator into productivity change and overall allocative change. To avoid any confusion, it is essential to distinguish when we talk about revenue inefficiency for a single period and when we talk about revenue inefficiency change over time. According to Farrell [2], we stated that the revenue inefficiency can be decomposed into technical and allocative inefficiency. However when we talk in a panel data context, we refer to revenue inefficiency change over time, productivity change and allocative change. This is due to the change of technical and allocative inefficiency as well as the shift in the technology between time $t$ and time $t+1$. Starting by equation (11), we obtain:

where RLI is the sum of the overall inefficiency change (OIEC) and the revenue Luenberger change (RLC).

As a next step, we decompose the overall inefficiency change (OIEC) into allocative inefficiency change (AIEC) and technical inefficiency change (TIEC) as follows: 


$$
\begin{aligned}
\text { OIEC }= & {\left[\frac{R\left(P_{t}, X_{t}\right)-P_{t} Y_{t}}{a}-\frac{R\left(P_{t+1}, X_{t+1}\right)-P_{t+1} Y_{t+1}}{b^{\prime}}\right] } \\
= & \underbrace{\left[\left(\frac{R\left(P_{t}, X_{t}\right)-P_{t} Y_{t}}{a}-D W A\left(X_{t}, Y_{t}\right)\right)-\left(\frac{R\left(P_{t+1}, X_{t+1}\right)-P_{t+1} Y_{t+1}}{b^{\prime}}-D W A\left(X_{t+1}, Y_{t+1}\right)\right)\right]}_{\text {AIEC }} \\
& +\underbrace{\left[D W A\left(X_{t}, Y_{t}\right)-D W A\left(X_{t+1}, Y_{t+1}\right)\right]}_{\text {TIEC }} .
\end{aligned}
$$

Additionally, we further decompose RLC into technological change (TC) and allocative technological change (ATC) as illustrated below.

$$
\begin{aligned}
R L C= & \frac{1}{2}\left[\frac{R_{t+1}\left(P_{t+1}, X_{t}\right)-P_{t+1} Y_{t}}{a^{\prime}}-\frac{R_{t}\left(P_{t}, X_{t}\right)-P_{t} Y_{t}}{a}\right] \\
& +\frac{1}{2}\left[\frac{R_{t+1}\left(P_{t+1}, X_{t+1}\right)-P_{t+1} Y_{t+1}}{b^{\prime}}-\frac{\left.R_{t}\left(P_{t}, X_{t+1}\right)-P_{t} Y_{t+1}\right]}{b}\right] \\
= & \frac{1}{2}\left[\left(D W A_{t+1}\left(X_{t}, Y_{t}\right)+A I_{t+1}\left(P_{t+1}, X_{t}, Y_{t}\right)\right)-\left(D W A_{t}\left(X_{t}, Y_{t}\right)\right.\right. \\
& \left.\left.+A I_{t}\left(P_{t} X_{t}, Y_{t}\right)\right)\right] \\
& \left.+\frac{1}{2}\left(D W A_{t+1}\left(X_{t+1}, Y_{t+1}\right)\right)+A I_{t+1}\left(P_{t+1}, X_{t+1}, Y_{t+1}\right)\right) \\
& -\left(D W A_{t}\left(X_{t+1}, Y_{t+1}\right)+A I_{t}\left(P_{t}, X_{t+1}, Y_{t+1}\right)\right) \\
= & \frac{1}{2}\left[\left(D W A_{t+1}\left(X_{t}, Y_{t}\right)-D W A_{t}\left(X_{t}, Y_{t}\right)\right)+\left(D W A_{t+1}\left(X_{t+1}, Y_{t+1}\right)\right.\right. \\
& \left.\left.-D W A_{t}\left(X_{t+1}, Y_{t+1}\right)\right]\right] \\
& +\frac{1}{2}\left[\left(A I_{t+1}\left(P_{t+1}, X_{t}, Y_{t}\right)-A I_{t}\left(P_{t}, X_{t}, Y_{t}\right)\right)+\left(A I_{t+1}\left(P_{t+1}, X_{t+1}, Y_{t+1}\right)\right.\right. \\
& \left.\left.-A I_{t}\left(P_{t}, X_{t+1}, Y_{t+1}\right)\right)\right] \\
= & T C+A T C .
\end{aligned}
$$

Combining the results of the first and second decomposition we obtain:

$R L I=T I E C+A I E C+T C+A T C$.

Hence

$R L I=T I E C+T C+A I E C+A T C=P C+A C$,

where $\mathrm{PC}$ is the Luenberger productivity change indicator based on the WADF proposed by Aparicio et al. [1], and AC is a Luenbergertype overall allocative change term. PC is composed of TIEC and TC, where TIEC measures the change in efficiency over time for the assessed DMU relative to each period frontier and TC measures the average shift between the two frontiers over time. On the other hand, AC is composed of AIEC and ATC. AIEC measures the gap change over time between revenue inefficiency and technical inefficiency, while ATC measures the gap change of average shift in revenue boundary and technological boundary.

After introducing and decomposing our revenue Luenberger indicator, we note that revenue progress is indicated by positive values and regress by negative values. The same can be applied to the rest of the components.

\section{Empirical application}

In this section, we consider an illustrative case of the applicability of the new methodology in the case of the French wine sector. France accounts for $16 \%$ of the world's total wine production and is the second largest wine producer in the world, with a production volume of $43.5 \mathrm{MhL}$ in 2016 [47]. The wine sector is a major contributor to the economic development of the country, being the second in the trade balance surplus of the French economy, just behind the aerospace. The wine sector accounts for $15 \%$ of agricultural revenues, while vines account for less than 3\% of the land used. There are 558,000 direct and indirect jobs related to wine industry in France, out of which 142,000 are wine producers, most of which are relatively small. The organization of wine production in France is highly centered on the system based on designations of origin and quality labels which involves over $90 \%$ of the French wine supply. This peculiarity imposes important issues concerning the efficient management of wine regions dedicated to wine growing. The Common Market Organization (CMO) measures adopted in 2008 included domestic and export sales promotion and changes to the planting-rights regime [48]. The wine sector in France is one of the rare economic sectors in the country which does not consider labor costs and vineyard surface areas as challenging factors for operations. The CMO wine policy related measures adopted by the European Union (EU) radically altered the logic of public support for this sector: instead of seeking to structure the supply of wine in Europe through plantation rights, distillation aids and strict rules on vinification processes, the reform was based on a logic which reasoned in terms of consumer demand for "quality wine" [49], the reduction of rules and encouraging EU wine merchants to access third country markets [50]. These measures sparked considerable protest and public demonstrations in France, in particular regarding plantation rights which led to the reduction of surface areas in almost all regions. The capacity of the French to adapt supply to international market demand, and revenues from foreign sales are considered to be vital for the economic efficiency of the wine regions and therefore of the whole wine sector. In this section, we consider nine major French wine regions in order to illustrate the applicability of the new methodology.

In our study, we consider the major French wine regions: Alsace, Beaujolais, Bordeaux, Bourgogne, Champagne, LanguedocRoussillon, Loire, Provence, and Rhone. We aim to track the revenue inefficiency of the nine major French regions over the 20042013 period, before and after the implementation of CMO policy. The data used in this study is provided from FranceAgriMer, ${ }^{2}$ where we account for two input and two output variables. The input variables are surface area (hectares) and number of winegrowers, whereas the output variables are the volume of the French protected designation of origin status, or appellation d'origine contrôlée (AOC) domestic sales in supermarkets and hypermarkets, and all wine foreign sales (hl). The choice of our variables are in line with the variables used in studies carried out by Aparicio et al. [27] and Vidal et al. [24]. It is important to note that land and labor are not the only inputs used in viticulture. However, we did not account for other variables such as energy use (fuel, gas, and electricity), fertilizers, and pesticides due to the lack of information on the public database.

Due to the limited number of DMUs and the variables enrolled in this application, we point out that this empirical analysis does

\footnotetext{
${ }^{2}$ FranceAgriMer is the national authority for agriculture and sea products, which is a public administrative establishment under government supervision (www franceagrimer.fr/).
} 
Table 1

The average and variance of the input and output variables for the 2004-2013 period.

\begin{tabular}{|c|c|c|c|c|}
\hline \multirow[t]{2}{*}{ Regions } & \multicolumn{2}{|c|}{ Average value of inputs } & \multicolumn{2}{|c|}{ Average value of outputs } \\
\hline & $\begin{array}{l}\text { Surface area } \\
\left(10^{3} \mathrm{ha}\right)\end{array}$ & $\begin{array}{l}\text { Number of winegrowers } \\
\left(10^{3}\right)\end{array}$ & $\begin{array}{l}\text { Domestic AOC sales } \\
\left(10^{3} \mathrm{hl}\right)\end{array}$ & $\begin{array}{l}\text { Foreign sales all wine } \\
\left(10^{3} \mathrm{hl}\right)\end{array}$ \\
\hline ALSACE & $\begin{array}{l}15.49 \\
(0.219)\end{array}$ & $\begin{array}{l}5.956 \\
(0.679)\end{array}$ & $\begin{array}{l}227.385 \\
(9.5)\end{array}$ & $\begin{array}{l}229.274 \\
(16.843)\end{array}$ \\
\hline BEAUJOLAIS & $\begin{array}{l}19.32 \\
(1.883)\end{array}$ & $\begin{array}{l}3.427 \\
(0.416)\end{array}$ & $\begin{array}{l}139.317 \\
(11.484)\end{array}$ & $\begin{array}{l}378.361 \\
(85.739)\end{array}$ \\
\hline BORDEAUX & $\begin{array}{l}119.89 \\
(3.93)\end{array}$ & $\begin{array}{l}8.942 \\
(1.073)\end{array}$ & $\begin{array}{l}1541.412 \\
(90.221)\end{array}$ & $\begin{array}{l}1998.682 \\
(268.776)\end{array}$ \\
\hline BOURGOGNE & $\begin{array}{l}30.83 \\
(0.284)\end{array}$ & $\begin{array}{l}6.293 \\
(0.691)\end{array}$ & $\begin{array}{l}214.813 \\
(6.866)\end{array}$ & $\begin{array}{l}674.499 \\
(63.792)\end{array}$ \\
\hline CHAMPAGNE & $\begin{array}{l}31.8 \\
(1.594)\end{array}$ & $\begin{array}{l}15.949 \\
(0.366)\end{array}$ & $\begin{array}{l}1344.991 \\
(45.6450)\end{array}$ & $\begin{array}{l}1013.012 \\
(85.866)\end{array}$ \\
\hline LANGUEDOC-ROUSSILLON & $\begin{array}{l}187 \\
(17.259)\end{array}$ & $\begin{array}{l}23.449 \\
(5.003)\end{array}$ & $\begin{array}{l}390.089 \\
(20.774)\end{array}$ & $\begin{array}{l}563.266 \\
(73.497)\end{array}$ \\
\hline LOIRE & $\begin{array}{l}58.32 \\
(2.4250)\end{array}$ & $\begin{array}{l}16.425 \\
(4.2890)\end{array}$ & $\begin{array}{l}678.606 \\
(48.6040)\end{array}$ & $\begin{array}{l}445.068 \\
(87.8070)\end{array}$ \\
\hline PROVENCE & $\begin{array}{l}47.31 \\
(1.978)\end{array}$ & $\begin{array}{l}17.124 \\
(2.37)\end{array}$ & $\begin{array}{l}482.192 \\
(31.547)\end{array}$ & $\begin{array}{l}93.880 \\
(32.972)\end{array}$ \\
\hline RHONE & $\begin{array}{l}142.43 \\
(9.457)\end{array}$ & $\begin{array}{l}20.289 \\
(3.014)\end{array}$ & $\begin{array}{l}878.424 \\
(30.007)\end{array}$ & $\begin{array}{l}804.703 \\
(70.77)\end{array}$ \\
\hline
\end{tabular}

Average (variance).

Table 2

Descriptive statistics for foreign prices.

\begin{tabular}{lllllllllll}
\hline Foreign prices in millions of Euros & 2004 & 2005 & 2006 & 2007 & 2008 & 2009 & 2010 & 2011 & 2012 & 2013 \\
\hline Average & 0.57 & 0.58 & 0.61 & 0.63 & 0.67 & 0.64 & 0.65 & 0.70 & 0.73 & 0.75 \\
Min & 0.20 & 0.19 & 0.21 & 0.23 & 0.23 & 0.22 & 0.23 & 0.26 & 0.28 & 0.29 \\
Max & 1.84 & 1.93 & 1.99 & 2.07 & 2.11 & 1.95 & 1.96 & 2.04 & 2.16 & 2.19 \\
\hline
\end{tabular}

Table 3

Descriptive statistics for domestic prices.

\begin{tabular}{lllllllllll}
\hline Domestic prices in millions of Euros & 2004 & 2005 & 2006 & 2007 & 2008 & 2009 & 2010 & 2011 & 2012 & 2013 \\
\hline Average & 0.59 & 0.58 & 0.59 & 0.61 & 0.63 & 0.64 & 0.66 & 0.68 & 0.69 & 0.72 \\
Min & 0.32 & 0.31 & 0.32 & 0.33 & 0.34 & 0.36 & 0.38 & 0.39 & 0.41 & 0.43 \\
Max & 1.45 & 1.42 & 1.51 & 1.59 & 1.62 & 1.56 & 1.56 & 1.64 & 1.66 & 1.68 \\
\hline
\end{tabular}

not cover all aspects of revenue inefficiency in the French wine sector. For this reason, we consider this application as an illustrative example for the proposed decomposition. We adopt an output oriented approach which focuses on strategies targeting sales and revenue maximization [50-52]. This approach is explained by the shift in wine supply mainly caused by grubbing up, crisis distillation and plantation rights schemes of CMO policy measures. The revenue inefficiency results are calculated based on CRS assumption with the aid of DEA excel Solver developed by Zhu [53].

Table 1 shows a summary of the input and output variables. We notice that Luengedoc-Roussillon accounts for the highest variance in terms of surface area and number of winegrowers. Whereas, one can notice that Bordeaux accounts for the highest variance in terms of domestic and foreign sales. If we take the variance of the variance for each variable among all regions, we notice that the highest variation refers to the foreign sales volume followed by the domestic sales, surface area and the number of winegrowers.

Regarding prices, Tables 2 and 3 show the descriptive statistics for foreign and domestic sales prices across the whole time period. It is obvious that there are big differences in prices among regions. Moreover, prices depend on many factors: such as harvest quality, distribution channels and significantly vary even within one region (e.g. maximum wine price in Burgundy is expressed in thousands of euros- around 50,000 euros - per bottle, while a minimum price remains under ten euros, in the Bordeaux region about $5 \%$ of wines are sold at prices over several hundreds of euros, the average price of $95 \%$ of wines is close to ten euros). Hence, it is difficult to provide an interpretation for them due to the lack of data regarding the different factors that affect them.

\subsection{Analysis and results}

In this section, we will describe the results obtained after applying the proposed methodology to the French wine sector. The analysis carried out is based on tracking the evolution of the revenue inefficiency for the 2004-2013 period. First, we start with the results of the revenue Luenberger indicator for each region as indicated in Table 4.

One can notice that all regions witnessed a revenue regress for the 2008-2009 year (i.e. during the period of CMO policy implementation) except for Languedoc-Roussillon, Provence and Rhone. Moreover, we can see that after the implementation of the CMO policy Loire, Provence and Rhone exhibit progress in all of the following years. If we closely examine the results of the RLI, a progress is witnessed over the whole 2004-2013 period only for Provence region, while other regions show different revenue trends across different years. Thus, in average terms we can say that all regions exhibit a progress after implementation of CMO policy, reflected in the average revenue index as illustrated in Table 9. It is worth noting that Provence accounts for the highest progress among all regions, with an average progress index of 2.202 after the implementation of CMO policy. ${ }^{3}$ We note that in case the assessed point does not belong to the technology, two possible sce-

\footnotetext{
${ }^{3}$ Interpreting the revenue Luenberger indicator value of Provence, i.e. 2.202, it is not so clear that the obtained value is the mean of two differences. To get a better interpretation of this value, one can apply a formulation of the Luenberger indicator based on a base period. For example, the ideas of the Global Malmquist productivity index [54], which uses a 'global' benchmark technology as a reference to calculate
} 
Table 4

Revenue Luenberger indicator.

\begin{tabular}{|c|c|c|c|c|c|c|c|c|c|}
\hline & ALSACE & BEAUJOLAIS & BORDEAUX & BOURGOGNE & CHAMPAGNE & LANGUEDOC-ROUSSILLON & LOIRE & PROVENCE & RHONE \\
\hline 2004-2005 & 0.045 & -0.044 & -0.045 & 0.180 & -0.074 & -1.009 & 0.533 & 5.196 & 0.543 \\
\hline 2005-2006 & 0.370 & 0.007 & 0.081 & 0.615 & 0.092 & 1.017 & 0.297 & 1.820 & -0.333 \\
\hline 2006-2007 & 0.056 & -0.044 & 0.051 & 0.620 & 0.035 & -0.304 & 0.225 & 0.779 & 0.305 \\
\hline 2007-2008 & 0.150 & -0.010 & -0.032 & -0.491 & -0.048 & 0.541 & -0.132 & 0.664 & -0.040 \\
\hline 2008-2009 & -0.045 & -0.078 & -0.052 & -0.385 & -0.167 & 0.141 & -0.806 & 1.804 & 0.096 \\
\hline 2009-2010 & 0.317 & 0.097 & 0.090 & 0.298 & 0.070 & -0.383 & 0.321 & 1.874 & 0.251 \\
\hline 2010-2011 & -0.317 & 0.260 & 0.127 & 0.415 & 0.051 & 0.241 & 0.150 & 2.007 & 0.409 \\
\hline 2011-2012 & -0.17 & -0.027 & 0.049 & 0.527 & -0.064 & 0.453 & 0.379 & 3.899 & 0.225 \\
\hline 2012-2013 & 0.322 & -0.132 & -0.004 & -0.369 & -0.030 & -0.164 & 0.074 & 1.030 & 0.087 \\
\hline Average RLI & & & & & & & & & \\
\hline before CMO & 0.156 & -0.023 & 0.014 & 0.231 & 0.002 & 0.062 & 0.231 & 2.115 & 0.119 \\
\hline Average RLI & & & & & & & & & \\
\hline after CMO & 0.083 & 0.049 & 0.065 & 0.218 & 0.007 & 0.037 & 0.231 & 2.202 & 0.250 \\
\hline
\end{tabular}

Table 5

Productivity change.

\begin{tabular}{|c|c|c|c|c|c|c|c|c|c|}
\hline & Alsace & Beaujolais & Bordeaux & Bourgogne & Champagne & Languedoc-Roussillon & Loire & Provence & Rhone \\
\hline $2004-2005$ & -0.031 & -0.131 & -0.000 & 0.105 & -0.017 & -0.444 & 0.197 & 1.601 & 0.137 \\
\hline $2005-2006$ & 0.147 & -0.018 & 0.009 & 1.056 & 0.035 & 0.502 & 0.203 & 0.659 & -0.037 \\
\hline 2006-2007 & 0.073 & 0.158 & 0.023 & 0.582 & 0.017 & -0.092 & 0.122 & 0.203 & 0.157 \\
\hline $2007-2008$ & -0.040 & -0.292 & -0.013 & -0.514 & -0.024 & 0.148 & -0.116 & -0.019 & -0.004 \\
\hline $2008-2009$ & -0.125 & -0.454 & 0.000 & -0.508 & -0.080 & -0.054 & -0.625 & 0.449 & 0.037 \\
\hline $2009-2010$ & 0.091 & 0.185 & 0.047 & 0.498 & 0.000 & -0.011 & 0.165 & 0.823 & 0.202 \\
\hline 2010-2011 & -0.024 & 0.090 & 0.068 & 0.261 & 0.000 & 0.177 & 0.168 & 0.845 & 0.186 \\
\hline 2011-2012 & -0.011 & -0.014 & 0.000 & 0.359 & -0.024 & 0.197 & 0.294 & 2.154 & 0.131 \\
\hline $2012-2013$ & 0.027 & -0.078 & 0.000 & -0.020 & -0.013 & 0.038 & 0.061 & 0.562 & 0.078 \\
\hline Average PC & & & & & & & & & \\
\hline before CMO & 0.038 & -0.071 & 0.005 & 0.308 & 0.004 & 0.029 & 0.102 & 0.611 & 0.064 \\
\hline $\begin{array}{l}\text { Average PC } \\
\text { after CMO }\end{array}$ & 0.021 & 0.046 & 0.029 & 0.275 & -0.009 & 0.100 & 0.172 & 1.096 & 0.149 \\
\hline
\end{tabular}

narios arise while assessing the revenue inefficiency in consecutive periods. One is to obtain a positive value for the revenue inefficiency, and the other possibility is to obtain negative value of the revenue efficiency i.e. the actual revenue could exceed the maximal revenue.

Second, we further examine the decomposition of the RLI to analyze the productivity change and the overall allocative change of the assessed regions. Starting with the productivity change, we divide the regions into two groups. The first group consists of regions that exhibit a productivity progress in all years following the implementation of the CMO while the second group consists of regions that exhibit a variable productivity change in all years following the implementation of the CMO. Bordeaux, Loire, Provence and Rhone belong to the first group. The second group includes Alsace, Beaujolais, Bourgogne, Champagne and Languedoc-Roussillon. The productivity change can be analyzed for all regions as illustrated in Table 5. This fact is due to the use of the WADF that avoids infeasibilities on assessing consecutive periods. Again, one can notice that Provence accounts for the highest productivity change index in all periods following the implementation of the CMO policy followed by Bourgogne, Loire, Rhone, LanguedocRoussillon, Beaujolais, Bordeaux, Alsace, and Champagne with an average productivity change index of $1.096,0.275,0.172,0.149$, $0.100,0.046,0.029,0.021$ and -0.009 respectively.

As we have shown earlier, the productivity change is composed of two terms: technical inefficiency change and technological change. According to Fig. 1, we can see that only Bordeaux had a zero value of technical inefficiency change from group one and Alsace, Beaujolais and Champagne from group two. Results show

all the distances, could be applied to define a Luenberger-type indicator based on the WADF for measuring revenue inefficiency over time.

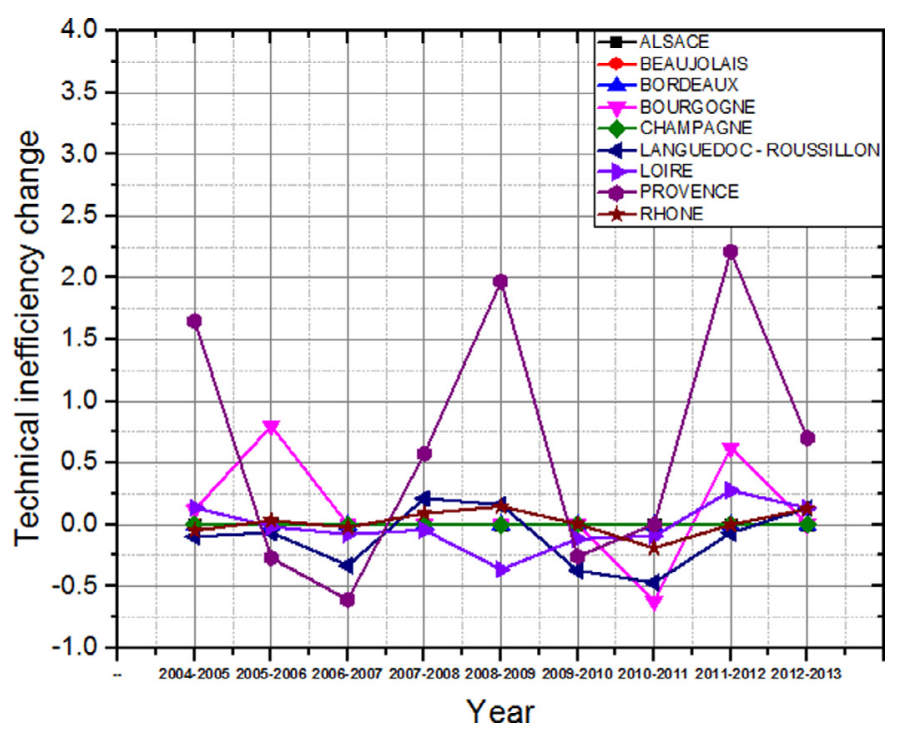

Fig. 1. Technical inefficiency change for all regions across the 2004-2013 period.

that the aforementioned regions were technically efficient for the whole period. ${ }^{4}$

In the case of technological change, we can see from Table 6 that all regions witness a regress during the implementation of the CMO policy period except for Bordeaux which exhibited no tech-

\footnotetext{
${ }^{4}$ We have also compared our results for decomposing revenue inefficiency with that provided by the DDF, considering $g=\left(0, Y_{0}\right)$ in the cross-sectional context. In this respect, we have checked that the technical inefficiency component in the case of the WADF is always greater or equal to the technical inefficiency component in the case of the DDF.
} 
Table 6

Technological change.

\begin{tabular}{|c|c|c|c|c|c|c|c|c|c|}
\hline & Alsace & Beaujolais & Bordeaux & Bourgogne & Champagne & Languedoc-Roussillon & Loire & Provence & Rhone \\
\hline 2004-2005 & -0.031 & -0.131 & 0.000 & -0.016 & -0.017 & -0.345 & 0.058 & -0.049 & 0.186 \\
\hline 2005-2006 & 0.147 & -0.018 & 0.009 & 0.256 & 0.035 & 0.566 & 0.219 & 0.929 & -0.072 \\
\hline 2006-2007 & 0.073 & 0.158 & 0.023 & 0.582 & 0.017 & 0.239 & 0.199 & 0.813 & 0.179 \\
\hline 2007-2008 & -0.040 & -0.292 & -0.013 & -0.514 & -0.024 & -0.065 & -0.073 & -0.594 & -0.094 \\
\hline 2008-2009 & -0.125 & -0.454 & 0.000 & -0.508 & -0.080 & -0.216 & -0.261 & -1.520 & -0.110 \\
\hline 2009-2010 & 0.091 & 0.185 & 0.047 & 0.498 & 0.000 & 0.361 & 0.281 & 1.083 & 0.197 \\
\hline 2010-2011 & -0.024 & 0.090 & 0.068 & 0.883 & 0.000 & 0.647 & 0.261 & 0.844 & 0.377 \\
\hline 2011-2012 & -0.011 & -0.014 & 0.000 & -0.262 & -0.024 & 0.263 & 0.018 & -0.059 & 0.131 \\
\hline 2012-2013 & 0.027 & -0.078 & 0.000 & -0.020 & -0.013 & -0.096 & -0.074 & -0.139 & -0.050 \\
\hline $\begin{array}{l}\text { Average TC } \\
\text { before CMO } \\
\text { Average TC }\end{array}$ & 0.038 & -0.071 & 0.005 & 0.078 & 0.004 & 0.099 & 0.102 & 0.275 & 0.05 \\
\hline after CMO & 0.021 & 0.046 & 0.029 & 0.275 & -0.009 & 0.294 & 0.122 & 0.432 & 0.164 \\
\hline
\end{tabular}

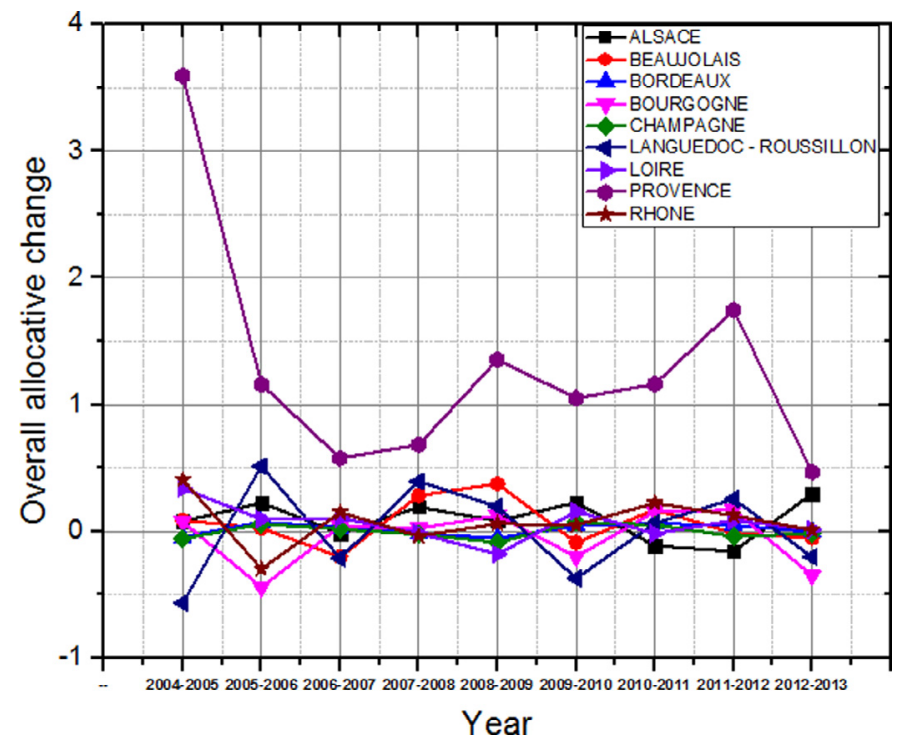

Fig. 2. Overall allocative change for all regions across the 2004-2013 period.

nological change. If we closely examine the figures among the regions themselves across different years, we can notice that most of the regions display a regress in the first period, during the CMO policy period and in the last period. However, if we examine the figures between the regions for each period, we can say that there is no standard pattern for the technological change evolution except for Bordeaux, which almost exhibits a positive technological change across all periods. Following the CMO policy period, in average terms, we can say that all regions witness a positive trend except for Champagne. Figures show that Champagne had a zero technological change in the first two periods following CMO policy, followed by a negative technological change in the last two periods, thus explaining its negative trend. Again, Provence accounts for the highest average technological change with a value of 0.432 .

On the other hand, we show in Fig. 2 the evolution of the overall allocative change for each region for the whole 2004-2013 period. It can be seen that Provence and Rhone are the only regions that have positive overall inefficiency change after the implementation of CMO policy. The rest of the regions exhibit both positive and negative overall allocative change.

One can assess which of the two terms (productivity change or overall allocative change) is the reason behind obtaining a positive or negative RLI. We note that we cannot express the aforementioned terms in terms of percentage. This fact is due to the existence of both negative and positive signs. Hence, it would be reasonable to address the following three cases. First, if both terms have a positive sign, then we can say that the RLI is boosted by both of them. However, if we compare which is bigger, we can conclude that the bigger term reflects a higher revenue progress. Secondly, if both terms are negative, then we can conclude that winemakers should improve their production both technically and allocatively. The bigger the term in absolute value is the reason behind causing more revenue regress. Finally, and in the third case, if the two terms have opposite signs, then we can definitely say that winemakers should focus on improving the negative term to boost revenue progress.

We show in Table 7 the term that should be improved for each region in each year to improve the RLI.

Table 8 shows the average of productivity change (APC) and the average of overall allocative change (AOAC) over the whole period for all regions. Figures indicate that the APC of Alsace, Beaujolais, Loire, and Provence is less than the AOAC while the average $A O A C$ is less than the APC for Bourgogne, Languedoc-Roussillon, and Rhone. In the case of Champagne, both terms are negative, which indicates that Champagne suffers from a revenue regress over time because of market changes and pricing issues. However, in the case of Bordeaux, we can see that both terms are positive and equal.

Next, we examine the contribution of APC and the AOAC component to revenue efficiency before and after the implementation of CMO. We also try to explore the changes of these components and their impact on revenue efficiency over time with possible implemented CMO policies that might have altered or introduced new strategies to adapt to new market changes.

\subsection{Contributions of $A P C$ and the $A O A C$ component to revenue efficiency before and after the implementation of CMO policy}

We have seen from Fig. 1 that Alsace, Beaujolais, Bordeaux and Champagne exhibit zero technical change over the 2004-2013 period. Thus, the productivity change is determined by the technological change. These regions exhibit technological progress and regress across different years. The technological change of Bordeaux is greater or equal to zero after the implementation of CMO. This reflects market changes that favor productivity change improvement. However, technological change in Champagne is less than or equal to zero after the implementation of CMO while the technological change of Alsace and Beaujolais exhibits both negative and positive values after the implementation of CMO policy.

To better understand these changes, we report in Table 9 the average RLI, APC and AOAC components for all regions before and after the implementation of the CMO policy.

Results show that these regions exhibit a revenue progress over time before and after the implementation of CMO except for Beaujolais. However, if we examine the figures closely, we notice that $A O A C$ is the factor that drives more improvement in revenue ef- 


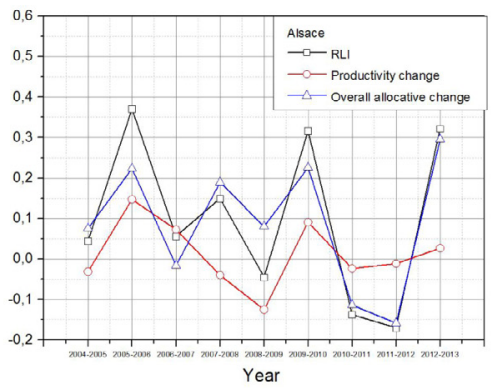

(a) Alsace

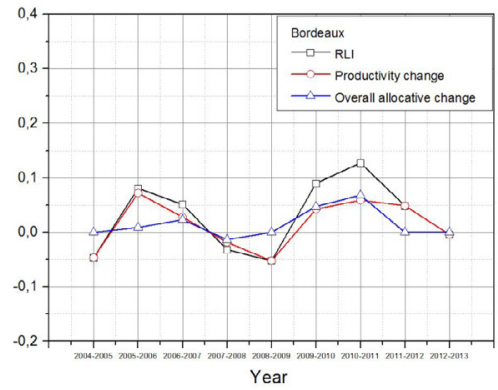

(c) Bordeaux

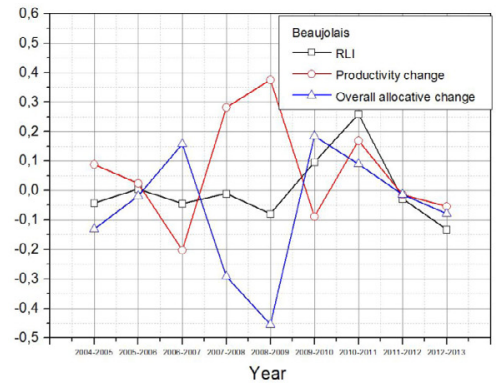

(b) Beaujolais

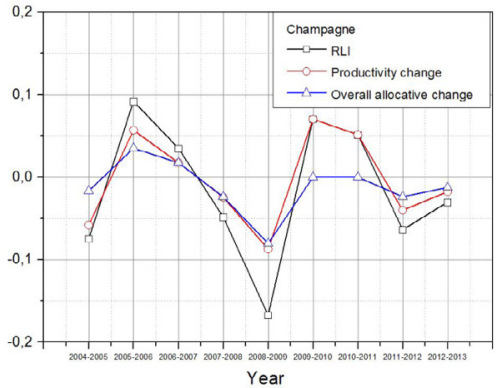

(d) Champagne

Fig. 3. Revenue Luenberger indicator and its components

Table 7

The term causing more revenue regress in each period.

\begin{tabular}{|c|c|c|c|c|c|c|c|c|c|}
\hline & Alsace & Beaujolais & Bordeaux & Bourgogne & Champagne & Languedoc-Roussillon & Loire & Provence & Rhone \\
\hline 2004-2005 & PC & PC & $A C$ & $A C$ & $A C$ & $A C$ & PC & PC & PC \\
\hline $2005-2006$ & PC & PC & PC & $\mathrm{AC}$ & PC & PC & $\mathrm{AC}$ & PC & $\mathrm{AC}$ \\
\hline $2007-2008$ & PC & PC & PC & PC & $A C$ and $P C$ & PC & PC & PC & PC \\
\hline 2008-2009 & PC & PC & AC & PC & $\mathrm{AC}$ & PC & PC & PC & PC \\
\hline 2009-2010 & PC & $A C$ & $A C$ & $\mathrm{AC}$ & PC & $\mathrm{AC}$ & $A C$ & PC & $\mathrm{AC}$ \\
\hline $2012-2013$ & PC & PC & $A C$ & $A C$ & $A C$ & $A C$ & $\mathrm{AC}$ & $A C$ & AC \\
\hline
\end{tabular}

Table 8

Average productivity change and overall allocative change for 2004-2103 period.

\begin{tabular}{lll}
\hline Regions & APC over all period & AOAC over all period \\
\hline Alsace & 0.012 & 0.09 \\
Beaujolais & -0.062 & 0.065 \\
Bordeaux & 0.015 & 0.015 \\
Bourgogne & 0.203 & -0.046 \\
Champagne & -0.125 & -0.004 \\
Languedoc-Roussillon & 0.052 & 0.008 \\
Loire & 0.053 & 0.064 \\
Provence & 0.809 & 1.311 \\
Rhone & 0.099 & 0.077 \\
\hline
\end{tabular}

ficiency in the case of Alsace and Bordeaux before and after the implementation of the CMO policy. In the case of Beaujolais and Champagne, the main factors that drive more improvement in revenue efficiency are not the same before and after the implementation of the CMO policy. For example, a regress in APC is witnessed in the case of Beaujolais before the implementation of CMO with a positive value of AOAC. However, APC improved after CMO policy in a way that even contributed to a greater extent than AOAC in improving revenue efficiency. The case is exactly the same in the case of Champagne, with altered roles of productivity change and overall allocative change. The only difference witnessed is that APC has a negative value after the implementation of CMO policy.

It might be explained that some regions such as Alsace and Bordeaux are managing their production efficiency (positive values of APC) well, in addition to their performance in the market. The progress in AOAC and its main contribution to revenue efficiency seems to reflect well-planned and focused pricing strategies and the promotion of their products in domestic and foreign markets. This is clearly reflected in the increase of their sales volumes within and outside Europe.

The aforementioned explanation can be also applied to Provence. It appears that Provence successfully improves its revenue efficiency by improving both of its APC and AOAC components at the highest level compared to other regions, as seen in Fig. 4. This proves that Provence has adapted well to market changes and CMO policy whether it is translated in better management of its production efficiency level or targeting new markets that absorb its supply capacity, mainly targeting rosé wine sales. Provence is the main producer of rosé wines in France and increasing consumer interest towards the rosé wine market might be the key to achieving such a remarkable revenue improvement.

On the other hand, Bourgogne suffers from negative values of AOAC before and after the implementation of CMO policy. This shows that its revenue progress over time is boosted by the APC 
Table 9

Revenue Luenberger Indicator and its average components before and after the implementation of CMO policy.

\begin{tabular}{llllllllll}
\hline & Alsace & Beaujolais & Bordeaux & Bourgogne & Champagne & Languedoc-Roussillon & Loire & Provence & Rhone \\
\hline APC & 0.037 & -0.071 & 0.005 & 0.307 & 0.003 & 0.029 & 0.101 & 0.611 & 0.063 \\
AOAC & 0.118 & 0.048 & 0.009 & -0.077 & -0.002 & 0.074 & 0.130 & 1.497 & 0.033 \\
ARLI & 0.155 & -0.023 & 0.013 & 0.231 & 0.001 & 0.102 & 0.231 & 2.108 \\
APC & 0.021 & 0.046 & 0.029 & 0.275 & -0.009 & 0.100 & 0.097 \\
AOAC & 0.062 & 0.003 & 0.037 & -0.057 & 0.016 & -0.063 & 0.172 & 1.096 & 0.149 \\
ARLI & 0.083 & 0.049 & 0.065 & 0.218 & 0.007 & 0.037 & 0.059 & 1.106 \\
\hline
\end{tabular}

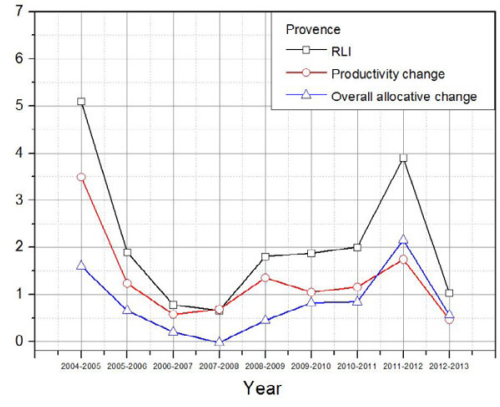

(a) Provence

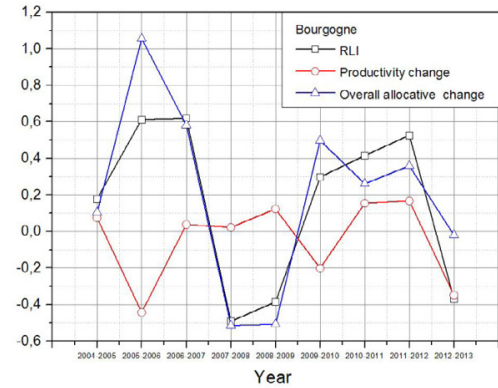

(b) Bourgogne

Fig. 4. Revenue Luenberger indicator and its components.

component only. It can be concluded that Bourgogne did not manage to target domestic and foreign markets by allocating best prices for its products. However, the positive values in the APC component could reflect a positive impact of CMO policy in reducing production surplus and better implemented strategies that aimed at eliminating waste.

Finally, Loire and Rhone exhibit revenue progress over time because of their AOAC and APC component. It seems that CMO policy altered the main contributor to revenue efficiency over time. AOAC (APC) contributed more than APC (AOAC) in improving revenue efficiency before the implementation of CMO policy, in the case of Loire and Rhone respectively. However, these components interchange their roles after CMO policy. Languedoc-Roussillon faces the same changes as Loire except the fact that it faces negative AOAC after the implementation of CMO policy. The changes in RLI, APC and AOAC over the specified one year periods are illustrated in Fig. 5.

It appears that the reduction in surface area and market conditions (i.e. APC component) favored the improvement of revenue efficiency at a higher rate than executed strategies related to AOAC component, in the case of Loire and Languedoc-Roussillon. Such witnessed improvements could be reflected in the development of bio wines in the Loire region and the implementation of innovative practices introduced in the Languedoc-Roussillon region. Improvements in AOAC are witnessed at a higher rate than APC in the case of Rhone after the implementation of CMO policy. Examining the figures, we can conclude that Rhone follows managerial strategies that tackle technical performance improvement as well as promoting and allocating best prices for its products in the markets.

\subsection{Discussion of findings}

The major results presented in Section 4.1 raise the following questions concerning the differences in revenue efficiency of French wine regions:

- Why is the Champagne region an exception compared to other regions with its negative average productivity change after the implementation of CMO policies? Why does this region have the lowest revenue progress, in average terms, among all regions following the implementation of CMO policies?
- Why does Provence account for the highest revenue progress and the highest average technological change?

- Why does the Bordeaux region exhibit almost no technological change after the implementation of CMO policies?

We have performed an additional comprehensive analysis to address these issues in greater depth. During the 2004-2013 period under review, all the French wine regions implemented important structural changes aimed at integrating small wine properties and expanding wine companies within the sector, accompanied by the reduction of vine areas. Another aim of the strategy was to reform the wine market as regards both enhancing the quality of wines and improving its competitiveness. The measures have proved to be a valuable tool for wine companies as they subsequently led to revenue progress in almost all regions (see Table 4).

The negative average productivity change after the implementation of CMO policies in the Champagne region could be related to the high level of fragmentation of land with inheritances. This phenomenon often results in the changes of the legal status of certain wine farmers, as some of them become just wine growers selling the grapes to other siblings, who then produce Champagne and sell it. We can witness from Fig. $6 a$ and $b$ a decrease in the volume of domestic and foreign sales of Champagne wines after the implementation of CMO policies. Champagne is quite a unique wine product which is dependent on the economy - when it is doing well, sales prosper but when the economy goes into a recession, the Champagne sales regress. That was the case in 2008, a year marked by the global economic crisis. Even the sales of internationally well-known Champagne brands (as Veuve Clicquot or Bollinger) decreased by 20 to $40 \%$. This drop in sales volume also addressed the shift in wine supply mainly caused by the resduced harvests and CMO policy measures concerning plantation rights schemes.

On the contrary, the thoughtful integration policy pursued in Provence, which is the leading region for rosé wine production, witnessed the highest revenue progress and the highest average technological change. A rising consumer interest in rosé wines in France and in other European wine markets over the last decade has also helped justify the remarkable improvement experienced 


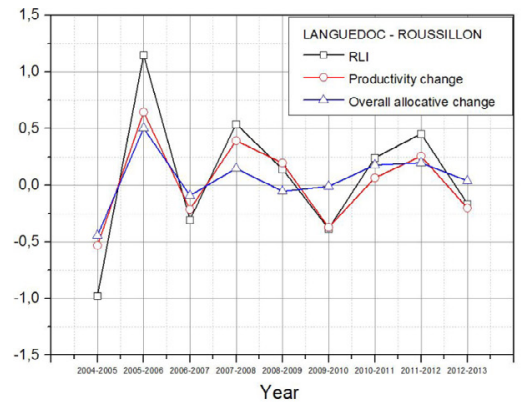

(a) Languedoc-Roussillon

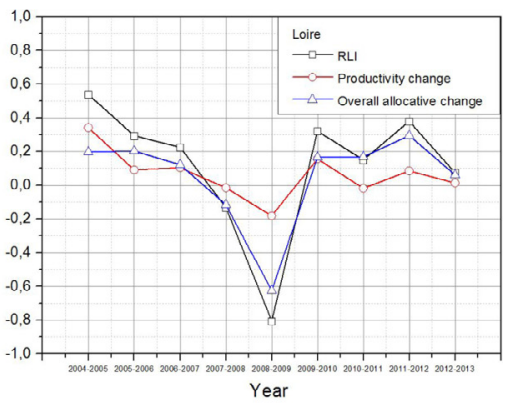

(b) Loire

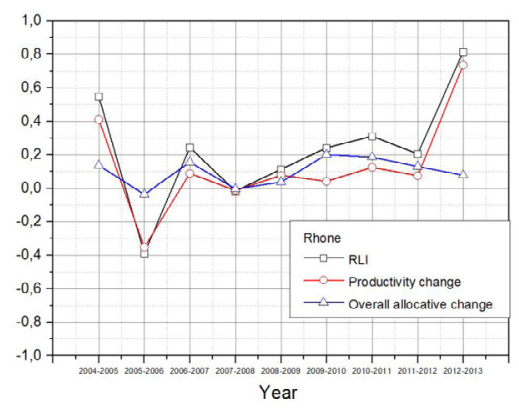

(c) Rhone

Fig. 5. Revenue Luenberger indicator and its components.

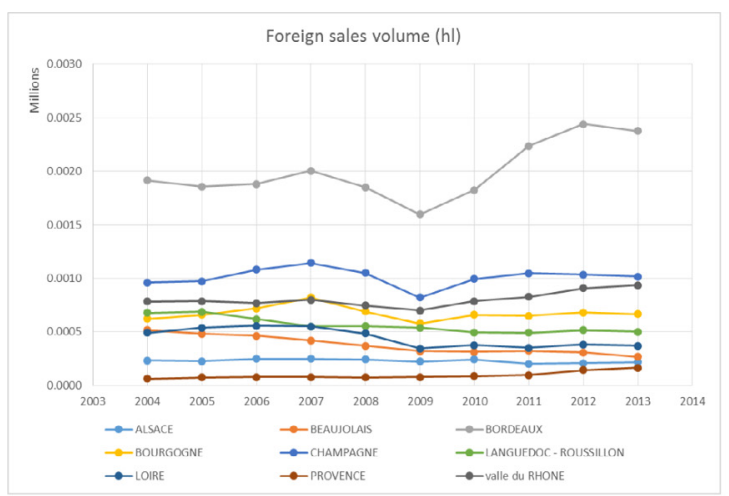

(a) Foreign sales volume by region

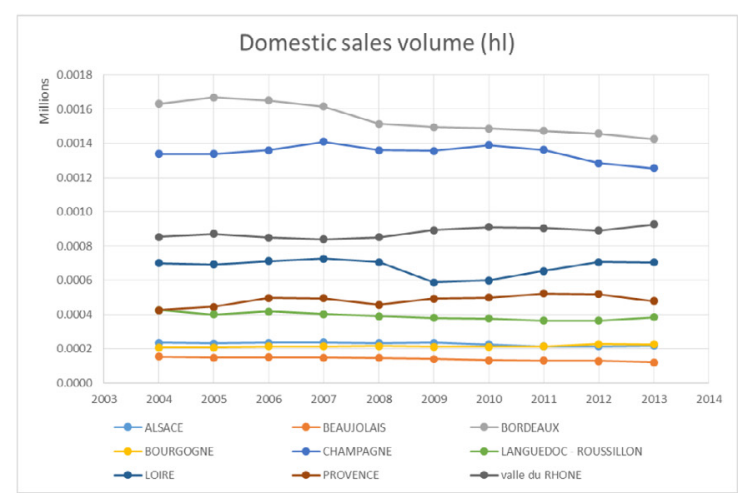

(b) Domestic sales volume by region

Fig. 6. Domestic and Foreign sales volume by region.

by this region in terms of revenue efficiency. This is echoed by the increase in foreign and domestic sales volume.

The Bordeaux region, which had difficulties to restructure, was caught up in 2008 by the unprecedented surge of interest by the Chinese market in its wines. This is reflected by the increase in the volume of foreign sales after 2009 (see, Fig. 6a). This incidental coincidence in time with the introduction of CMO policies, helped to maintain its position in the market throughout the periods which we have revealed in our study for this region. This effect of wine export growth in China, though on a smaller scale, was also observed for the Bourgogne region.

The differences in wine region situations and prospects have been unveiled in "The strategic plan of the wine sector development in France and the prospects of regional policies through 2025", adopted in June 2014 by FranceAgriMer [52]. Globally, France has consolidated its high price and low volume strategic position in export markets over the whole 2004-2013 period. This has usually been the result of a deliberate strategy of the wine regions themselves and the structural changes imposed by CMO poli- cies. Therefore, France has maintained its supremacy in the world wine market in the face of these changes [55].

\section{Conclusion}

In this paper, we have introduced and decomposed revenue inefficiency change into productivity change and allocative change based on the WADF and a Luenberger-type indicator. This revenue Luenberger indicator is based on the WA model in DEA, which accounts for slacks, thus reflecting more realistic values in the technical inefficiency change component. This implies that we guarantee an unbiased estimation for the allocative change component hence providing better information related to the misallocation of input-output mixes. In this respect, we provided a new dual correspondence relationship between revenue inefficiency and the output-oriented WA model, when points lie outside the reference technology, i.e. while assessing consecutive periods.

Then, as an application for our proposed model, we have studied the revenue inefficiency evolution of the nine major French 
wine regions for the 2004-2013 period. Although there are several studies in the literature about technical inefficiencies of wineries, there were no studies on revenue inefficiency evolution. Each of the decomposition terms of the revenue Luenberger indicator was discussed for the French wine regions over all periods. Furthermore, we have discussed three scenarios to determine whether the productivity change or the allocative change causes more revenue regress of the regions in each period. In average terms, productivity change reflected a higher rate for revenue regress in the case of Alsace, Beaujolais, Loire, and Provence. However, overall allocative change was identified to cause more revenue regress in the case of Bourgogne, Languedoc-Roussillon, and Rhone regions, while productivity change and overall allocative change were equally identified to be the reason behind revenue regress (progress) for Champagne (Bordeaux), respectively.

Results have shown that CMO policy has altered the strategies followed by different regions to adapt to new market changes. Beaujolais, Champagne, Languedoc-Roussillon, Loire and Rhone witnessed changes in productivity components that had an impact on revenue efficiency over time, while Alsace, Bordeaux and Bourgogne maintained the same component that boosts their revenue efficiency over time. Finally, this study could be extended in the future to account for scale efficiency and to incorporate more variables that explain economic efficiency in the French wine sector. Furthermore, the availability of more recent data could help investigate the trend of economic change following the implementation of CMO. Within such improvements, comparisons could be carried out to examine which policies are mainly responsible for affecting such economic changes.

\section{Acknowledgments}

We thank two anonymous referees and the corresponding associate editor for providing constructive comments and help. Juan Aparicio is grateful to the Spanish Ministry of Economy and Competitiveness for supporting this research, through grant MTM201679765-P (AEI/FEDER, UE).

\section{References}

[1] Aparicio J, Pastor JT, Vidal F. The weighted additive distance function. Eur. J. Oper. Res. 2016;254(1):338-46

[2] Farrell MJ. The measurement of productive efficiency. J. R. Stat. Soc. Ser. A General) 1957;120(3):253-90.

[3] Debreu G. The coefficient of resource utilization. Econometrica 1951:273-92.

[4] Shepard RW. Cost and Production Functions. Princeton: Princeton University 1953.

[5] Maniadakis N, Thanassoulis E. A cost Malmquist productivity index. Eur. J. Oper. Res. 2004; 154(2):396-409.

[6] Zhu N, Liu Y, Emrouznejad A, Huang Q. An allocation Malmquist index with an application in the China securities industry. Oper. Res. 2016:1-23.

[7] Juo J-C, Fu T-T, Yu M-M, Lin Y-H. Profit-oriented productivity change. Omega 2015;57:176-87

[8] Grifell-Tatjé E, Lovell C, Pastor J. A quasi-Malmquist productivity index. J. Product. Anal. 1998;10(1):7-20.

[9] Lovell CK, Pastor JT, Turner JA. Measuring macroeconomic performance in the OECD: a comparison of European and non-European countries. Eur. J. Oper. Res. 1995;87(3):507-18.

[10] Tone K. A slacks-based measure of efficiency in data envelopment analysis. Eur. J. Oper. Res. 2001;130(3):498-509.

[11] Tone ECO. Malmquist productivity index. Handbook Data Envelop. Anal. 2004;71:203.

[12] Grifell-Tatjé E, Lovell CAK. Profits and productivity. Manage. Sci. 1999;45(9):1177-93.

[13] Asaftei G. The contribution of product mix versus efficiency and technical change in us banking. J. Bank. Finance 2008:32(11):2336-45.

[14] Juo J-C, Fu T-T, Yu M-M. Non-oriented slack-based decompositions of profit change with an application to Taiwanese banking. Omega 2012;40(5):550-61.

[15] Delord B, Montaigne É, Coelho A. Vine planting rights, farm size and economic performance: do economies of scale matter in the French viticulture sector? Wine Econ Policy 2015;4(1):22-34.

[16] Charnes A, Cooper WW, Rhodes E. Measuring the efficiency of decision making units. Eur. J. Oper. Res. 1978;2(6):429-44.
[17] Banker RD, Charnes A, Cooper WW. Some models for estimating technical and scale inefficiencies in data envelopment analysis. Manage. Sci. 1984:30(9):1078-92.

[18] Townsend RF, Kirsten J, Vink N. Farm size, productivity and returns to scale in agriculture revisited: a case study of wine producers in South Africa. Agri. Econ. 1998;19(1):175-80

[19] Lecocq S, Visser M. Spatial variations in weather conditions and wine prices in Bordeaux. J. Wine Econ. 2006;1(02):114-24.

[20] Barros CP, Santos JG, et al. Comparing the productive efficiency of cooperatives and private enterprises: the Portuguese wine industry as a case study. J. Rural Cooperat. 2007;35(2):109

[21] Arandia Miura A, Aldanondo Ochoa A. Technical and environmental efficiency of organic vs. conventional vineyards. Revista Española de Estudios Agrosociales y Pesqueros (España) 2007.

[22] Henriques PdS, Carvalho MdS, Costa F, Pereira R, Godinho M, et al. Characterization and technical efficiency of Portuguese wine farms.. Ciência e Técnica Vitivinícola 2009;24(2):73-80.

[23] Fuller KB, Alston JM, Sambucci OS. The value of powdery mildew resistance in grapes: evidence from California. Wine Econ. Policy 2014;3(2):90107.

[24] Vidal F, Pastor J, Borras F, Pastor D. Efficiency analysis of the designations of origin in the Spanish wine sector. Spanish J. Agri. Res. 2013;11(2):294-304.

[25] Cooper WW, Pastor JT, Borras F, Aparicio J, Pastor D. BAM: a bounded adjusted measure of efficiency for use with bounded additive models. J. Product. Anal. 2011;35(2):85-94.

[26] Pastor J, Vidal F, Borrás F, Pastor D. The quality wine sector in Spain. An efficiency analysis. In: International Conference on Business and Information (BA 2012). Sapporo. Japan; 2012.

[27] Aparicio J, Borras F, Pastor JT, Vidal F. Accounting for slacks to measure and decompose revenue efficiency in the Spanish designation of origin wines with DEA. Eur. J. Oper. Res. 2013;231(2):443-51.

[28] Nerlove M.. Estimation and identification of Cobb-Douglas production functions1965;

[29] Chambers RG, Chung Y, Färe R. Profit, directional distance functions, and Nerlovian efficiency. J. Optim. Theory Appl. 1998;98(2):351-64.

[30] Ray SC. Data Envelopment Analysis: Theory and Techniques for Economics and Operations Research. Cambridge University Press; 2004.

[31] Cooper W, Pastor JT, Aparicio J, Borras F. Decomposing profit inefficiency in DEA through the weighted additive model. Eur. J. Oper. Res. 2011;212(2):411-16

[32] Cooper WW, Park KS, Pastor JT. RAM: a range adjusted measure of inefficiency for use with additive models, and relations to other models and measures in DEA. J. Product. Anal. 1999;11(1):5-42.

[33] Lovell CK, Pastor JT. Units invariant and translation invariant DEA models. Oper. Res. Lett. 1995;18(3):147-51.

[34] Cooper W, Pastor J. Generalized efficiency measures (GEMS) and model relations for use in DEA. J. Product. Anal. 1996.

[35] Prieto AM, Zofio JL. Evaluating effectiveness in public provision of infrastructure and equipment: the case of Spanish municipalities. Journal of productivity Analysis 2001;15(1):41-58

[36] Cook WD, Hababou M. Sales performance measurement in bank branches. Omega 2001;29(4):299-307.

[37] Chambers RG, Färe R, Grosskopf S. Productivity growth in APEC countries. Pacific Econ. Rev. 1996;1(3):181-90.

[38] Chambers RG, Pope RD. Aggregate productivity measures. Am. J. Agri. Econ. 1996;78(5):1360-5.

[39] Chambers RG. Exact nonradial input, output, and productivity measurement. Econ. Theory 2002;20(4):751-65.

[40] Briec W, Kerstens K. Infeasibility and directional distance functions with application to the determinateness of the Luenberger productivity indicator. J. Optim. Theory Appl. 2009;141(1):55-73.

[41] Aparicio J, Monge JF, Ortiz L, Pastor JT. Changes in productivity in the virgin olive oil sector: an application to protected designations of origin in Spain. Spanish J. Agri. Res. 2016;14(3):0104.

[42] Grifell-Tatjé E, Lovell CK. A note on the Malmquist productivity index. Econ. Lett. 1995:47(2):169-75

[43] Ray SC, Desli E. Productivity growth, technical progress, and efficiency change in industrialized countries: comment. Am. Econ. Rev. 1997;87(5):1033-9.

[44] Balk BM. Scale efficiency and productivity change. J. Product. Anal. 2001:15(3):159-83.

[45] Lovell CK. The decomposition of Malmquist productivity indexes. J. Product. Anal. 2003;20(3):437-58.

[46] Kapelko M, Horta IM, Camanho A, Lansink AO. Measurement of input-specific productivity growth with an application to the construction industry in Spain and Portugal. Int. J. Prod. Econ. 2015;166:64-71.

[47] OIV. World wine production estimated at $259 \mathrm{mhl} ; 2016$. Available at http://www.oiv.int/en/oiv-life/2016-world-wine-production-estimated-at259-mhl.

[48] Montaigne E. European wine market issues and prospects in the context of the changes to the common market organization for wine. Agri. Res. Econ. Update 2010;13(6):9-11.

[49] Zago A. A nonparametric analysis of production models with multidimensional quality. Am. J. Agri. Econ. 2009;91(3):751-64

[50] Itçaina X, Roger A, Smith A. Implementating the EU's 2008 wine reform: differentiated institutionalisation compared. In: Paper Presented at ECPR Conference; 2011 
[51] Roumegoux M.. VIN/VIN 2020, Plan stratégique de valorisation de la filiére vitivinicole Française á l'Horizon 2020; 2008. Available at http://www. ladocumentationfrancaise.fr/var/storage/rapports-publics/094000171.pdf.

[52] FranceAgriMer. Plan stratégique sur les perspectives de la filiére vitivinicole á l'horizon 2025; 2014. Available at http://www.k-ber.net/wp-content/uploads/ 2014/07/PlanStrat\%C3\%A9giqueVin.pdf

[53] Zhu J. Quantitative models for performance evaluation and benchmarking: data envelopment analysis with spreadsheets, 213. Springer; 2014.
[54] Pastor JT, Lovell CK. A global Malmquist productivity index. Econ. Lett. 2005;88(2):266-71.

[55] Lewis G., Zalan T., Schebella M.. A Strategic Approach to the Analysis of Global Wine Industry Positioning; 2014. Available at http://academyofwinebusiness. com/wp-content/uploads/2014/07/BM07_Lewis_Geoffrey.pdf. 